\title{
Distance of Tumor to Skin as a Predictive Marker for Axillary Lymph Node Metastasis in Cases of Breast Carcinoma - A Retrospective Study
}

\begin{abstract}
Background: Breast cancer is arising as the most common cancer among women. Axillary lymph node status is considered as one of the most important predictors of survival in breast cancer and a very important component to the staging system. The tumors under the skin have abundant access to the dermal lymphatic and have an increased chance of metastasizing to draining lymph nodes. Aim of the Study: To evaluate whether distance of tumor to skin can be considered as a predictor for lymph node metastasis. Materials and Methods: This was a retrospective study on all operated cases of infiltrating mammary carcinoma from January 2013 to December 2016. Both lumpectomy and mastectomy specimens with invasive carcinoma component were included in the study. The distance of the tumor was measured from the base of the epidermis of the skin to the anterior margin of the tumor on gross examination or microscopically the closest invasive carcinoma component. The distance was measured, tabulated, and correlated with the nodal status on axillary node dissection. Also, compared are the other parameters such as size, site, and grade of the tumor. Results: Out of 200 patients enrolled, positive nodes were seen in $67.5 \%$ (135) of cases, of which tumor with distance from skin $<0.3 \mathrm{~cm}$ show maximum nodal positivity $(64.4 \%)$ and maximum cases with $\mathrm{N} 2$ and N3 disease (48.8\%). Most important and significant finding was that $100 \%$ cases with tumor size corresponding in T2 size with skin invasion either grossly or microscopically and T3 size tumor with microscopically involving epidermis was positive for metastatic deposits in axillary nodes and 10/11 cases (90\%) in T4 stage were positive. Conclusion: The distance of tumor from skin is an important predictor for Axillary lymph nodal metastasis in invasive breast cancers. Closer the tumor, the incidence of axillary nodal metastasis increases. Hence, distance of tumor from skin should be considered while evaluating a breast cancer patient.
\end{abstract}

Keywords: Breast carcinoma, distance from skin, nodal status

\section{Introduction}

Breast cancer is the most common type of cancer in females worldwide, and the burden is increasing day by day in both developed and developing countries. According to National cancer registry in India, breast cancer is now leading cancer in females surpassing the cervical cancer, at both urban and rural locations across India. ${ }^{[1]}$

The success of treatment is based on early detection and proper staging. Tumor size and axillary nodal status are still vital prognostic indicators of breast cancer. The Large size of tumor and increased number of involved nodes are associated with poorer prognosis and increased rate of recurrences and mortality. ${ }^{[2]}$

According to literature, various other prognostic markers are age, vascular

This is an open access journal, and articles are distributed under the terms of the Creative Commons Attribution-Non Commercial-ShareAlike 4.0 License, which allows others to remix, tweak, and build upon the work non-commercially, as long as appropriate credit is given and the new creations are licensed under the identical terms.

For reprints contact: reprints@medknow.com invasion, hormonal receptors status, menopausal status, histological grade, nuclear grade, lymphovascular invasion, DNA ploidy, and various tumor markers. However, axillary lymph node status is still the single most important prognostic indicator in breast cancer. ${ }^{[3,4]}$

The seventh edition of tumor node metastasis staging in breast cancer by American Joint Committee on Cancer (AJCC) includes the size of the tumor and the nodal status as the most important prognostic factors. The nodal status is divided into three $\mathrm{N}$ stages according to AJCC guidelines: N1 (1-3 nodes positive), N2 (4-9 nodes positive), and N3 (more than 9 nodes positive). ${ }^{[5]}$

Previous studies have demonstrated that lymph node status correlates well with the tumor size, i.e., larger the tumor size,

How to cite this article: Ojha SS, Jain RA, Nilkanthe RG, Meenai FJ, Abhishek S, Amit HK. Distance of tumor to skin as a predictive marker for axillary lymph node metastasis in cases of breast carcinoma - A retrospective study. Indian J Med Paediatr Oncol 2018;39:321-5.

\section{Sandeep S Ojha, Rubal A Jain, Ramrao G Nilkanthe, Farah J Meenai, Sharma Abhishek ${ }^{1}$, Haritwal K Amit}

Departments of Pathology and

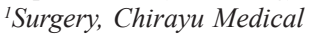
College and Hospital, Bhopal, Madhya Pradesh, India

Address for correspondence: Dr. Sandeep S Ojha, Department of Pathology, Chirayu Medical College and Hospital, Bhopal Indore Highway, Near Bairagarh, Bhopal - 462 030, Madhya Pradesh, India. E-mail: drsandy0582@ gmail.com

Access this article online Website: www.ijmpo.org DOI: 10.4103/ijmpo.ijmpo_26_17 Quick Response Code:

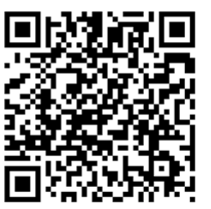


worse is the prognosis. According to literature, it has been demonstrated that histologic grading, lymphovascular invasion, and location of the tumor also affects the nodal positivity. ${ }^{[6-8]}$

Most of the lymphatics drain the breast through the cutaneous lymphatic drainage system which consists of a superficial plexus of channels that lie within the dermis and a deeper network of lymphatic channels that runs with the mammary ducts in the subareolar area. Hence, any tumor close to these structures has access to abundant lymphovascular network and has an increased chance to metastasize. ${ }^{[9]}$ Thus, we proposed that tumors close to the skin should have a higher rate of axillary lymph node metastasis at diagnosis. The aim of the present study was to know whether the distance from overlying skin or nipple and areola increase the risk of lymph nodal metastasis. There are only a handful of studies done on the correlation of skin distance with nodal status and to the best of our knowledge; this will be the first study from India demonstrating this factor.

\section{Materials and Methods}

This was a retrospective analysis of all operated case of breast cancer (includes lumpectomy with Axillary dissection and mastectomy) performed at a tertiary care cancer institute over a period of 4 years (January 2013 to November 2016). A total of 200 cases were studied. All the cases with only ductal carcinoma in situ component and previous history of surgery, hormonal therapy, previous radiotherapy, or neoadjuvant chemotherapy as well as cases in male sex were excluded from the study. Only cases with a primary diagnosis of infiltrating mammary carcinoma operated either as lumpectomy with axillary dissection or modified radical mastectomy was included in this study.

The data were retrieved from the reports stored at histopathology section of department of pathology. The data were recorded from the reports available to note the site, size, grading, and distance of tumor from skin and nodal status of the disease. The data were tabulated and analyzed. Slides of the cases were reviewed in case of any doubt. All the variables were analyzed and correlation with nodal metastasis was studied. Location of the tumors in the breast was noted and tumors were categorized based on location as located in upper outer quadrant (UOQ), upper inner quadrant (UIQ), lower outer quadrant (LOQ), lower inner quadrant (LIQ), and retro-areolar region. Tumors were separated based on AJCC as T1/2/3/4 and N1/2/3. We also segregated tumors with $\mathrm{T} 2$ size as $\mathrm{T} 2 / 4$ where skin was ulcerated or microscopically involved. Tumors with T3 size where tumor was microscopically infiltrating the epidermis were also segregated as T3/4. This was done to know whether smaller tumor (T2 size) infiltrating the skin grossly or microscopically and T3 tumors with microscopic skin invasion have more chances of metastasis to lymph nodes. Tumors were graded based on the "Nottingham combined histologic grade (Elston-Ellis modification of Scarff-Bloom-Richardson grading system)." ${ }^{[10]}$

Tumor grade was compared with the nodal status of the disease and was tabulated and evaluated. Patients were divided into two groups according to breast cancer distance from the skin: $<3 \mathrm{~mm}$ group and $>3 \mathrm{~mm}$ group. This was based on the superficial lymphatic drainage of the breast as described in literature is located from the skin to a $3 \mathrm{~mm}$ depth. ${ }^{[11,12]}$

\section{Results}

In this study, the woman in $5^{\text {th }}$ decade had increased incidence of breast cancer (133 cases; 66.5\%). The left side of breast was most commonly involved (68.7\%), and UOQ was most frequently involved (93 cases; 68.8\%).

On correlating site of the lesion with lymph node involvement [Table 1], the N2 and N3 nodal status were most commonly seen with tumors located in UOQ $(61.5 \%)$ followed by LOQ (12\%) and retro-areolar region $(12 \%)$. While $36.8 \%$ of tumors in UIQ and $41.6 \%$ in LIQ showed $\mathrm{N} 2 / \mathrm{N} 3$ nodal status. N1 nodal status was seen in $22.5 \%$ of cases with the most common location being UOQ.

Out of total 200 cases, $5.5 \%, 58.5 \%$, and $22 \%$ tumors belong to $\mathrm{T} 1, \mathrm{~T} 2$, and $\mathrm{T} 3$, respectively [Table 2]. The most common $\mathrm{T}$ size showing $\mathrm{N} 2$ and above nodal status was T2 (19.5\%) followed by T3 (12.5\%) and T1 (0.5\%) excluding cases with T4 and T2/T3 with skin invasion.

\begin{tabular}{lcccccccc}
\hline \multicolumn{7}{l}{ Table 1: Correlating site of tumor and nodal positivity } \\
\hline $\begin{array}{l}\text { Tumor based } \\
\text { on location }\end{array}$ & N0 & N1 & N2 & N3 & $\begin{array}{c}\text { Total } \\
\text { cases }\end{array}$ & $\begin{array}{c}\text { Total nodes } \\
\text { positive (\%) }\end{array}$ & $\begin{array}{c}\text { Total nodes } \\
\text { negative (\%) }\end{array}$ \\
\hline $\begin{array}{l}\text { Upper outer } \\
\text { quadrant }\end{array}$ & 30 & 35 & 38 & 20 & 123 & $93(75.5)$ & $30(24.5)$ \\
$\begin{array}{l}\text { Upper inner } \\
\text { quadrant }\end{array}$ & 10 & 2 & 5 & 2 & 19 & $9(47.3)$ & $10(52.6)$ \\
$\begin{array}{l}\text { Lower outer } \\
\text { quadrant }\end{array}$ & 10 & 4 & 8 & 2 & 24 & $14(58.3)$ & $10(41.7)$ \\
$\begin{array}{l}\text { Lower inner } \\
\text { quadrant }\end{array}$ & 9 & 1 & 0 & 0 & 10 & $1(10)$ & $9(90)$ \\
$\begin{array}{l}\text { Retro-areolar } \\
\text { Total }\end{array}$ & 6 & 3 & 10 & 5 & 24 & $18(75)$ & $6(25)$ \\
\hline
\end{tabular}

\begin{tabular}{lccccccc}
\hline \multicolumn{7}{l}{ Table 2: Correlating size of tumor and nodal positivity } \\
\hline $\begin{array}{l}\text { Tumor } \\
\text { based on } \\
\text { tumor size }\end{array}$ & N0 & N1 & N2 & N3 & Total & $\begin{array}{c}\text { Total nodes } \\
\text { positive (\%) }\end{array}$ & $\begin{array}{c}\text { Total nodes } \\
\text { negative (\%) }\end{array}$ \\
\hline T1 & 7 & 3 & 1 & 0 & 11 & $4(33.3)$ & $7(66.7)$ \\
$\mathrm{T} 2$ & 48 & 30 & 25 & 14 & 117 & $69(58.9)$ & $48(41.1)$ \\
$\mathrm{T} 2 / 4$ & 0 & 0 & 3 & 1 & 4 & $4(100)$ & 0 \\
$\mathrm{~T} 3$ & 9 & 10 & 14 & 11 & 44 & $35(79.5)$ & $9(20.5)$ \\
$\mathrm{T} 3 / 4$ & 0 & 1 & 9 & 3 & 13 & $13(100)$ & 0 \\
$\mathrm{~T} 4$ & 1 & 1 & 8 & 1 & 11 & $10(90.9)$ & $1(9.09)$ \\
Total & 65 & 45 & 60 & 30 & 200 & $135(67.5)$ & $65(32.5)$ \\
\hline
\end{tabular}


N1 nodal status was seen in $22.5 \%$ of cases and is seen with all sizes (T1-6.6\%, T2-66.6\%, T3-22.4\%) excluding $\mathrm{T} 4$ and T2/T3 with skin invasion.

In this study, a distance of skin from the tumor was calculated and was correlated with the nodal status [Table 3]. Positive nodes were seen in 67.5\% (135) of cases, of which tumor with distance from skin less than 0.3 $\mathrm{cm}$ show maximum nodal positivity ( 87 of $135=64.4 \%$ ) and maximum cases with $\mathrm{N} 2$ and N3 disease (66 cases of $135=48.8 \%)$.

Most significant was the finding that [Table 2] 100\% cases with tumor size corresponding in T2 stage with skin invasion either grossly or microscopically in T3 stage tumors were positive for metastatic deposits in axillary region and 10/11 cases (90\%) in T4 stage were positive. Hence, showing a positive result to our proposition. One case with T4 stage with negative nodes showed microscopically medullary type of morphology. Furthermore, tumors in outer upper quadrant were an independent predictor of axillary lymph node positivity (75.5\%). Correlation of nodal status with Modified Scarf Bloom Richardson grading was also studied [Table 4]. Grade II was associated with maximum nodal positivity percentage $(71.2 \%)$.

\section{Discussion}

Several factors are known to affect the biological behavior of breast cancer. These include the clinical and demographic features, pathological characteristics, nodal involvement, and the molecular factors within the breast tumor itself. ${ }^{[13]}$

The exact role that each of these may have on the biological behavior of breast cancer is an area of increasing interest, including their role in the regional spread of the disease. However, their impact on treatment until now continued to be an area of research interest only.

Table 3: Correlation of nodal status with distance of tumor from skin

\begin{tabular}{|c|c|c|c|c|c|c|c|}
\hline \multirow{2}{*}{$\begin{array}{l}\text { Distance of } \\
\text { tumor from } \\
\text { skin }(\mathrm{cm})\end{array}$} & \multicolumn{4}{|c|}{$\begin{array}{l}\text { Lymph node } \\
\text { status }\end{array}$} & \multirow[t]{2}{*}{ Total } & \multirow[t]{2}{*}{$\begin{array}{l}\text { Total nodes } \\
\text { positive }(\%)\end{array}$} & \multirow[t]{2}{*}{$\begin{array}{c}\text { Total nodes } \\
\text { negative }(\%)\end{array}$} \\
\hline & No & N1 & N2 & N3 & & & \\
\hline$<0.3$ & 11 & 21 & 44 & 22 & 98 & 87 & 11( \\
\hline$>0.3$ & 54 & 24 & 15 & 9 & 102 & $48(47)$ & $54(53)$ \\
\hline Total & 65 & 45 & 59 & 31 & 200 & $135(67.5)$ & $65(32.5)$ \\
\hline
\end{tabular}

Table 4: Correlation of nodal status with grading of tumor

\begin{tabular}{|c|c|c|c|c|c|c|c|}
\hline \multirow[t]{2}{*}{$\begin{array}{l}\text { Tumor } \\
\text { grading }\end{array}$} & \multicolumn{4}{|c|}{$\begin{array}{c}\text { Lymph node } \\
\text { status }\end{array}$} & \multirow[t]{2}{*}{ Total } & \multirow[t]{2}{*}{$\begin{array}{c}\text { Total positive } \\
\text { nodes }(\%)\end{array}$} & \multirow[t]{2}{*}{$\begin{array}{c}\text { Total negative } \\
\text { nodes }(\%)\end{array}$} \\
\hline & No & N1 & N2 & N3 & & & \\
\hline Grade I & 2 & 1 & 1 & 0 & 4 & $2(50)$ & $2(50)$ \\
\hline Grade II & 15 & 12 & 20 & 5 & 52 & $37(71.2)$ & $15(28.8)$ \\
\hline Grade III & 48 & 32 & 38 & 26 & 144 & $96(66.7)$ & $48(33.3)$ \\
\hline Total & 65 & 45 & 59 & 31 & 200 & $135(67.5)$ & $65(32.5)$ \\
\hline
\end{tabular}

Although tumor characteristics and molecular markers contribute to the understanding of breast cancer biology, axillary lymph node status remains one of the most reliable prognostic factors and is used as a guide for adjuvant breast cancer treatment. ${ }^{[14-16]}$

Identifying preoperative predictors of positive nodes helps guide the neoadjuvant therapy or surgical plan of choice and help patients become better psychologically prepared for axillary lymph node dissection (ALND) if required.

The three-dimensional lymphatic microanatomy of the breast is not well-known, despite the many studies reporting on the lymphatic drainage pathways from the breast and advances in breast sentinel lymphatic mapping particularly the superficial lymphatic drainage. Several reports have proposed that the dermal lymphatic pathway defines the clinically relevant breast cancer metastatic pathway and suggest that lymphatic supply is less abundant or available in the breast parenchyma than that in the superficial dermal and subdermal layers. ${ }^{[17,18]}$ This hypothesis has been supported by several studies that investigated sentinel lymph node biopsy (SLNB) methods.

Although SLNB is replacing ALND for axillary staging and is emerging as the new standard of care, there is a lack of standardized methodology for the procedure.

Axillary lymph node biopsy remains the best way to evaluate the presence of node metastases. It is also important in locoregional disease control. However, it is associated with complications such as lymphedema, shoulder stiffness, breast edema, seroma formation, upper limb numbness, and brachial plexopathy. ${ }^{[19,20]}$

Thus, finding an independent predictor of axillary lymph node positivity is highly valuable preposition both for the treating surgeon as well as the patient.

However, only a few reports have investigated tumor proximity to the skin and evaluated its relationship with axillary node metastasis. ${ }^{[17,21]}$ In this study, breast cancer distance from the skin $<3 \mathrm{~mm}$ resulted in greater axillary node metastasis and was highly significant $(P<0.001)$.

Ansari et al..$^{[21]}$ reported that more superficial tumors are associated with axillary node metastasis at diagnosis. They reviewed 233 breast cancers in T2 and T3 and found that decreasing tumor distance from the skin was significantly associated with positive axillary lymph nodes in a multivariate analysis.

Cunningham et al.$^{[17]}$ reported that tumors closer to the skin are more likely to have metastasis to the axillary nodes. They reviewed $209 \mathrm{~T} 1$ and T2 invasive breast cancer cases and determined an apparent threshold of approximately $1.4 \mathrm{~cm}$ from the skin. None of the cancers with a distance $>1.4 \mathrm{~cm}$ (26 cancers) had axillary node metastasis. However, the findings were based on radiological evaluation, unlike our study. 
Chao et $a l .{ }^{[18]}$ proposed that palpable tumors are closer to the dermal lymphatics compared with nonpalpable tumors, and that this explains why palpable tumors more frequently metastasize to the axillary lymph nodes compared with nonpalpable tumors.

Although tumor palpability is an independent risk factor for axillary node metastasis, it is insufficient to use as a parameter to predict axillary node metastasis as its affected by several other factors, including physician subjectivity, tumor size, breast tumor depth, hardness, ethnicity, body weight, menopausal status, hormone use, and elasticity of the mass and surrounding tissue..$^{[22,23]}$

Siddiqui et al. ${ }^{[6]}$ in multivariate analysis observed that only the tumor size, skin and nipple involvement and disease in the outer quadrants of the breast were predictive for axillary node involvement.

Similarly, our study also observed greater axillary lymph node positivity with advanced tumor stage more so in cases with proximity to overlying skin.

\section{Conclusion}

We found the distance of skin from underlying tumor as an independent predictive factor in for the presence of axillary lymph node metastases. With this information, either radiologically or intraoperative/postoperation evaluation of mastectomy specimen, we can select women who are likely to be node negative and give better preoperative counseling with information to patients regarding the probability of requiring further axillary dissection. This will empower patients in the participation of the management of their disease and possibility of follow-up surgery.

Not all cases of duct carcinoma will metastasize to lymph nodes. Even tumors of higher nuclear grade may be localized. According to literature, the lymph node metastasis was more commonly associated with tumors of larger size and with obvious lymphovascular emboli. However, it was also noticed that tumors of smaller size can also present with Axillary nodal metastasis. Anatomically, dermis of skin and nipple and areola has a dense network of lymphatics, and tumor close to the skin or nipple and areola may present with metastasis even with a smaller size. Hence tumor with smaller size but closer to skin should be managed as a tumor which is potentially capable of metastasis, and careful examination should be made to evaluate axillary nodal status.

The study is probably the first in Indian population, and more studies need to be conducted on larger patient groups for more conclusive interpretations and outcome.

\section{Financial support and sponsorship}

Nil.

\section{Conflicts of interest}

There are no conflicts of interest.

\section{References}

1. Ghoncheh M, Momenimovahed Z, Salehiniya H. Epidemiology, incidence and mortality of breast cancer in Asia. Asian Pac J Cancer Prev 2016;17:47-52.

2. Kroman N, Wohlfahrt J, Mouridsen HT, Melbye M. Influence of tumor location on breast cancer prognosis. Int $\mathrm{J}$ Cancer 2003;105:542-5.

3. Eom YH, Kim EJ, Chae BJ, Song BJ, Jung SS. The distance between breast cancer and the skin is associated with axillary nodal metastasis. J Surg Oncol 2015;111:824-8.

4. Saez RA, McGuire WL, Clark GM. Prognostic factors in breast cancer. Semin Surg Oncol 1989;5:102-10.

5. Edge SB, Byrd DR, Carducci MA, Compton CC, editors. AJCC Cancer Staging Manual. $7^{\text {th }}$ ed. New York: Springer; 2009.

6. Siddiqui T, Khan S, Kayani N, Pervez S, Salam A. Clinical, pathological and molecular factors predicting axillary node involvement in primary breast cancer in Pakistani women. J Pak Med Assoc 2002;52:192-5.

7. Chadha M, Chabon AB, Friedmann P, Vikram B. Predictors of axillary lymph node metastases in patients with $\mathrm{T} 1$ breast cancer. A multivariate analysis. Cancer 1994;73:350-3.

8. Chua B, Ung O, Taylor R, Boyages J. Frequency and predictors of axillary lymph node metastases in invasive breast cancer. ANZ J Surg 2001;71:723-8.

9. Nathanson SD, Wachna DL, Gilman D, Karvelis K, Havstad S, Ferrara $\mathrm{J}$, et al. Pathways of lymphatic drainage from the breast. Ann Surg Oncol 2001;8:837-43.

10. Ellis IO, Elston CW. Histologic grade. In: O'Malley FP, Pinder SE, editors. Breast Pathology. Philadelphia, PA: Elsevier; 2006. p. 225-33.

11. Suami H, Pan WR, Taylor GI. Historical review of breast lymphatic studies. Clin Anat 2009;22:531-6.

12. Pavlista D, Eliska O. Cutaneous and subcutaneous lymphatic drainage of the breast. Lymphology 2005;38:92-102.

13. DeMichele A, Weber BL. Recent advances in breast cancer biology. Curr Opin Oncol 1997;9:499-504.

14. Fisher B, Bauer M, Wickerham DL, Redmond CK, Fisher ER, Cruz $\mathrm{AB}$, et al. Relation of number of positive axillary nodes to the prognosis of patients with primary breast cancer. An NSABP update. Cancer 1983;52:1551-7.

15. Colleoni M, Zahrieh D, Gelber RD, Holmberg SB, Mattsson JE, Rudenstam CM, et al. Site of primary tumor has a prognostic role in operable breast cancer: The international breast cancer study group experience. J Clin Oncol 2005;23:1390-400.

16. Mansour EG, Ravdin PM, Dressler L. Prognostic factors in early breast carcinoma. Cancer 1994;74:381-400.

17. Cunningham JE, Jurj AL, Oman L, Stonerock AE, Nitcheva DK, Cupples TE, et al. Is risk of axillary lymph node metastasis associated with proximity of breast cancer to the skin? Breast Cancer Res Treat 2006;100:319-28.

18. Chao C, Edwards MJ, Abell T, Wong SL, Simpson D, McMasters KM, et al. Palpable breast carcinomas: A hypothesis for clinically relevant lymphatic drainage in sentinel lymph node biopsy. Breast J 2003;9:26-32.

19. Jatoi I. Management of the axilla in primary breast cancer. Surg Clin North Am 1999;79:1061-73.

20. Hoe AL, Iven D, Royle GT, Taylor I. Incidence of arm swelling following axillary clearance for breast cancer. $\mathrm{Br} \mathrm{J}$ Surg 
1992;79:261-2.

21. Ansari B, Morton MJ, Adamczyk DL, Jones KN, Brodt JK, Degnim AC, et al. Distance of breast cancer from the skin and nipple impacts axillary nodal metastases. Ann Surg Oncol 2011;18:3174-80.

22. Tafra L, Essner R, Brenner RJ, Giuliano AE. Nonpalpable versus palpable invasive breast tumors treated with breast-conserving surgical management. Am Surg 1996;62:395-9.

23. Silverstein MJ, Gierson ED, Waisman JR, Colburn WJ, Gamagami P. Predicting axillary node positivity in patients with invasive carcinoma of the breast by using a combination of $\mathrm{T}$ category and palpability. J Am Coll Surg 1995;180:700-4. 